\title{
Diverse chromosome complements in the functional gametes of interspecific hybrids of MT- and A-karyotype Lycoris spp.
}

\author{
Yu-Chu Chang $\cdot$ Chou-Tou Shii $\cdot$ Yi-Ching Lee • \\ Mei-Chu Chung
}

Received: 4 November 2012/ Accepted: 25 February 2013/Published online: 19 March 2013

(C) The Author(s) 2013. This article is published with open access at Springerlink.com

\begin{abstract}
The karyotype and numeric changes in chromosomes among taxa of Lycoris (spider lilies) have been attributed to whole-arm rearrangements; however, the history of karyotype evolution of Lycoris is still ambiguous. In the natural habitat, one-third of Lycoris taxa are interspecific hybrids that are mainly sterile and extremely diverse in morphologies. Lycoris are geophytes with the reproductive stage initiated inside the bulbs during the storage period, which brings some inconveniences in collecting meiotic materials for studying chromosome pairing. The partial fertility of an artificial F1 interspecific hybrid between $L$. aurea $(2 n=14)$ and L. radiata $(2 n=22)$ provides an alternative option for tracing the meiotic process in F1 hybrids. The chromosome compositions of those functional gametes generated by the F1 hybrid could be recovered according to the chromosome complements of backcross progenies. We perform genomic in situ hybridization (GISH) analysis on somatic chromosomes of 34
\end{abstract}

\author{
Y.-C. Chang · Y.-C. Lee · M.-C. Chung ( $\varangle)$ \\ Institute of Plant and Microbial Biology, Academia Sinica, \\ Taipei 11529, Taiwan, ROC \\ e-mail: bomchung@gate.sinica.edu.tw \\ Y.-C. Chang \\ e-mail: roger04188@yahoo.com.tw \\ Y.-C. Lee \\ e-mail: ycl20022002@yahoo.com.tw \\ Present Address: \\ Y.-C. Chang \\ Tainan District Agricultural Research and Extension Station, \\ Council of Agriculture, Executive Yuan, Tainan, Taiwan, ROC \\ C.-T. Shii \\ Department of Horticulture, National Taiwan University, \\ Taipei, Taiwan, ROC \\ e-mail: shiict@ntu.edu.tw
}

BC1 plants $(2 n=14-22)$ to reveal chromosomal divergences in number and composition of those functional gametes. GISH results also indicated a high homology between the MT- and A-genomes of Lycoris, reflecting on the partial fertility and frequently homoeologous recombination at meiosis of the F1 interspecific hybrids. The diverse chromosome complements and recombinant patterns presented in these functional gametes suggested that interspecific hybridization is an important force in driving diversification among Lycoris species. We suggest that the MT-karyotype genome may be the ancestral type in $L y c$ oris, and some other chromosomal rearrangements in addition to centromeric fission may have played roles in the karyotype evolution of Lycoris.

Keywords Lycoris - GISH - Recovered gamete · Karyotype evolution · Fusion-fission

\section{Introduction}

Numerical changes of chromosomes within genera are the clearest and most basic features in karyotype analyses of plant cytotaxonomy. However, variations in chromosome number only are often insufficient to interpret karyotype evolution among related organisms (Guerra 2008). Although knowledge of karyotype evolution is complex and ambiguous, some mechanisms of karyotype evolution among related species, such as Robertsonian fusion and fission mechanism, are well accepted (Schubert and Lysak 2011). Robertsonian fusion and fission alter the chromosomal structure by rearranging whole chromosomal arms, which changes the chromosomal symmetry and number, but keeps the number of major chromosome arms (nombre fondamantal NF) constant in the new complement. This 
mechanism has been identified as an important force in driving animal speciation; however, few examples have been reported in plants (Jones 1998). Among them, Lycoris is one of the earliest examples reported.

The genus Lycoris (Amaryllidaceae) contains about 30 taxa with different chromosome numbers $(2 n=12-44)$ and different ploidy $(2 x-4 x)$. Three types of chromosomes, including metacentrics (M-type), telocentrics (T-type), and acrocentrics (A-type), were identified in chromosome complements of Lycoris (Kurita 1986). The most important feature of the chromosome complements of Lycoris is that the total number of major chromosome arms of each complement is constant, with a multiple of $11(\mathrm{NF}=11)$ (Kurita 1988). According to the chromosome complements, Lycoris taxa were grouped into A, MT, and MT-A karyotypes. Taxa of the A- or MT- karyotype are fertile diploids, whereas those of the MT-A karyotype are interspecific hybrids and are mainly sterile (Kurita and Hsu 1998). In the natural habitat, about one-third of Lycoris taxa have the MT-A karyotype. Interspecific hybridization and subsequent polyploidization in natural habitats have been considered crucial forces driving the evolution of Lycoris (Kurita and Hsu 1996). Speciation and phylogenetic relationships in Lycoris have been extensively studied by morphological, cytological, and molecular approaches (Kurita 1987; Lee and Kim 1987; Hsu et al. 1994; Chung 1999; Hayashi et al. 2005). However, continuous variation in morphological and physiological features of Lycoris still challenged to reach a satisfactory classification of Lycoris taxa (Kurita and Hsu 1998).

Interspecific hybrids of Lycoris can be obtained by embryo-rescue techniques (Ma et al. 2001). F1 hybrids of L. aurea (golden spider lily, $2 n=14,8 \mathrm{M}+6 \mathrm{~T}$ ) and four different A-karyotype species (red spider lilies, $2 n=22$, 22A) can reproduce functional male gametes $(24.7-29.1 \%)$ with $\mathrm{NF}=11$, but all of them are female infertile (Shii et al. 1997; Wu et al. 2005). These F1 hybrids are valuable pollen parents for Lycoris breeding to obtain progenies with novel combinations. Some progenies (BC1) have been obtained by backcrossing these F1 hybrids to either of the parents or by test-crossing to other relative diploid species, which have various chromosome numbers $(2 n=14-22)$ and extremely diverse flower shapes and colors (Wu et al. 2005). The diverse karyotypes and appearance of the progenies suggest homoeologous chromosome pairing and subsequent recombination occurring at meiosis of F1 interspecific hybrids. Conventional observation on the chromosome configurations of the F1 hybrids at meiosis allows examining structural and functional homologies between parental genomes of an interspecific hybrid. However, collecting meiotic specimens of Lycoris is inconvenient because they are geophytes with hysteranthous leaves and with the reproductive stage initiated inside the bulbs during the storage period (Dafni et al. 1981). Thus, the developing anthers with pollen mother cells at suitable meiotic stage cannot be identified unless the bulbs are sacrificed. The partial fertility of these F1 interspecific hybrids of MT- and A-type Lycoris provides an alternative option for tracing the meiotic process in F1 hybrids. When F1 hybrids are used as the pollen parent in backcross/testcross, the chromosome complements of functional gametes produced by the F1 hybrids can be recovered based on the karyotypes of their progenies (Wu et al. 2005).

With well-developed genomic in situ hybridization (GISH) technique, one can cytologically discriminate closely related genomes and precisely dissect the chromosome pairing behaviors at meiosis of interspecific hybrids (Benavente et al. 2008). For better discrimination, the totalgenome DNA of another closely related species without labeling is usually used as competitor (blocking agent) to probe DNA in GISH (Anamthawat-Jonsson et al. 1990). The amount of blocking DNA is determined by the phylogenetic distance between both genomes. As we have reported previously, GISH with suitable amount of blocking DNA enabled revealing genomic affinities between Paphiopedilum species, lady's-slipper orchids (Lee et al. 2011).

The chromosome complements in functional pollen reproduced by $\mathrm{F} 1$ interspecific hybrids could be recovered from $\mathrm{BC} 1$ progenies by backcrossing $\mathrm{F} 1$ interspecific hybrids to each of the parents. We performed GISH on somatic chromosomes of $34 \mathrm{BC} 1$ progenies derived from F1 interspecific hybrid $(2 n=18,4 \mathrm{M}+3 \mathrm{~T}+11 \mathrm{~A})$ between Lycoris aurea $(2 n=14,8 \mathrm{M}+6 \mathrm{~T})$ and $L$. radiata $(2 n=22,22 \mathrm{~A})$. A high frequency of homoeologous recombination events has occurred over all chromosomes in these F1 interspecific hybrids at meiosis. GISH results suggested that the genomic composition of $L$. aurea (MTkaryotype) and L. radiata (A-karyotype) is highly homologous, but still diverse enough to be discriminated by GISH with a suitable amount of blocking DNA.

\section{Materials and methods}

\section{Plant materials}

The F1 interspecific hybrid L. aurea $(2 n=14=8 \mathrm{M}+$ $6 \mathrm{~T}) \times L$. radiata $(2 n=22=22 \mathrm{~A})$ was indicated hereafter as AR hybrid. $\mathrm{BC} 1$ progenies were obtained by backcrossing the AR hybrid (pollen parent) with $L$. aurea (AAR), with $L$. radiata (RAR), or with $L$. sprengeri (SAR) (Table 1). These plants had different flower types and colors (Fig. 1). Plants were grown in pots with a soil-less medium and slow-release fertilizers in the greenhouse at 
Table 1 Names and parentage of the plant materials used in this study

\begin{tabular}{lll}
\hline Name & $\begin{array}{l}\text { Parentage } \\
\text { combination }\end{array}$ & $\begin{array}{l}\text { Chromosome } \\
\text { composition }^{\text {a }}\end{array}$ \\
\hline LA $($ L. aurea $)$ & & $2 n=14,8 \mathrm{M}+6 \mathrm{~T}$ \\
LR $($ L. radiata $)$ & & $2 n=22,22 \mathrm{~A}$ \\
AR hybrid & $($ L. aurea $) \times$ & $2 n=18$, \\
& $($ L. radiata $)$ & $4 \mathrm{M}+3 \mathrm{~T}+11 \mathrm{~A}$ \\
AAR & $($ L. aurea $) \times \mathrm{AR}$ & $2 n=14-22$ \\
RAR & $($ L. radiata $) \times \mathrm{AR}$ & \\
SAR & (L. sprengeri $) \times \mathrm{AR}$ &
\end{tabular}

${ }^{a}$ Three types of chromosomes are metacentrics (M), telocentrics (T), and acrocentrics (A)
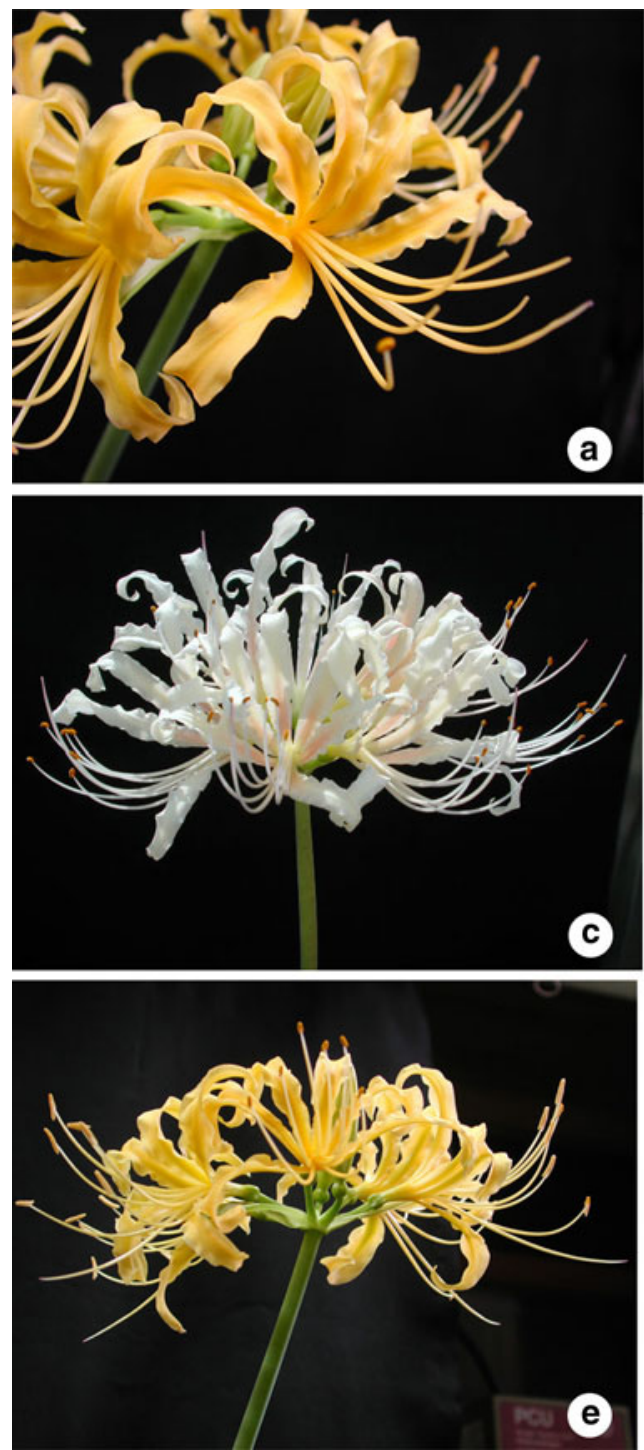

Fig. 1 Flowers of some accessions investigated in this study. a Gold spider lily: Lycoris aurea. b Red spider lily: L. radiata. c, d F1 interspecific hybrid of Lycoris aurea and L. radiata (AR) showing
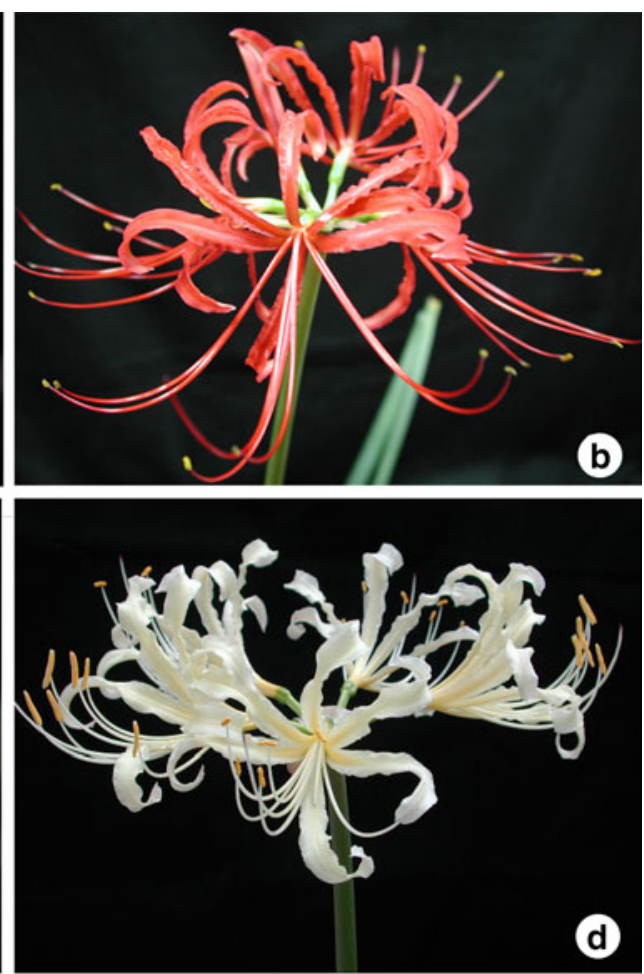

the Department of Horticulture of National Taiwan University, Taipei.

Preparation of total genomic DNA probes and blocking DNA

Total genomic DNA was extracted from fresh leaves by CTAB method (Gawel and Jarret 1991), and then stored at $-20{ }^{\circ} \mathrm{C}$. In each GISH hybridization experiment, either one of two parental genomic DNA of AR hybrid was labeled and used as probe and the other without labeling was used as competitor DNA (blocking DNA). For preparing probe DNA, total genomic DNA was mechanically sheared to fragments of $2.5-3.0 \mathrm{~kb}$, and then labeled with

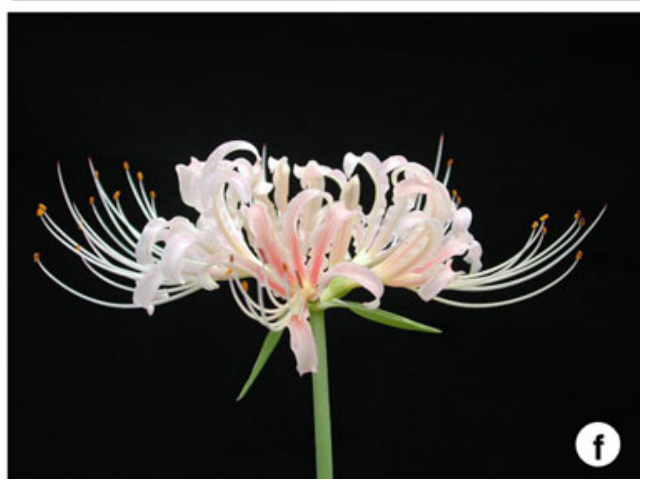

non-parental morphologic features and flower colors. The flower colors of most F1 were ivory-white to pale-pink. e One accession of AAR. f One accession of RAR 
digoxigenin-11-dUTP by nick translation (Roche Diagnostics, Penzberg, Germany). For preparing blocking DNA, total genomic DNA was autoclaved for 5-7 min to obtain fragments at an average length of 50-100 bp.

Chromosome preparation, GISH, and telomerefluorescence in situ hybridization (FISH)

Sample collection, treatment, and chromosome preparation were performed as previously described (Chung et al. 2008; Chang et al. 2009). In brief, young root tips were treated with $2 \mathrm{mM}$ 8-hydroxyquinoline at $18{ }^{\circ} \mathrm{C}$ for $4 \mathrm{~h}$ to accumulate mitotic metaphase nuclei, fixed in ethanol:acetic acid (3:1) overnight, and then stored at $-20{ }^{\circ} \mathrm{C}$. The fixed root tips were macerated with an enzyme mixture containing $6 \%$ pectinase (Sigma Chemical Co., St. Louis, MO, USA) and $6 \%$ cellulase (Onozuka R-10, Yakult Honsha, Japan) in $75 \mathrm{mM} \mathrm{KCl}(\mathrm{pH} 4.0)$ at $37{ }^{\circ} \mathrm{C}$ for 75-80 min. Softened tissue was squared on a slide in a few drops of methanol:acetic acid (3:1), and then air-dried. Slides with well-spread chromosome preparations were selected for GISH.

GISH was performed as the protocol of rDNA-FISH used on Lycoris chromosomes (Chang et al. 2009) with minor modification. In the hybridization mixture $(20 \mu \mathrm{L}$ per slide), the amount of blocking DNA was 60 -fold excess of labeled probe. Chromosome preparations were denatured in $75 \%$ formamide $/ 2 \mathrm{X}$ SSC at $80{ }^{\circ} \mathrm{C}$ for $90 \mathrm{~s}$. Hybridization signals were visualized by use of rhodamineconjugated anti-digoxigenin antibody (Roche Diagnostics $\mathrm{GmbH}$, Germany). Chromosomes were counterstained with 4', 6-diamidino-2-phenylindole (DAPI) in an antifade solution (Vector Laboratories, CA, USA).
The telomere at chromosome of Lycoris consists of the human-type telomeric repeats (TTAGGG) $n$ instead of the Arabidopsis-type repeats (TTTAGGG) $n$ found in most plants (Sykorova et al. 2003). The telomere probe for FISH was amplified and labeled with digoxigenin-11-dUTP by PCR (PCR Dig-labeling Mix, Roche Diagnostics GmbH, Germany) with the sequence (TTAGGG) 5 as primer in the absence of template (Ijdo et al. 1991). The PCR program involved initial denaturing for $15 \mathrm{~min}$ at $95^{\circ} \mathrm{C} ; 10$ cycles of $60 \mathrm{~s}$ at $94{ }^{\circ} \mathrm{C}, 30 \mathrm{~s}$ at $55^{\circ} \mathrm{C}$, and $60 \mathrm{~s}$ at $72{ }^{\circ} \mathrm{C} ; 30$ cycles of $60 \mathrm{~s}$ at $94{ }^{\circ} \mathrm{C}, 30 \mathrm{~s}$ at $60{ }^{\circ} \mathrm{C}, 90 \mathrm{~s}$ at $72{ }^{\circ} \mathrm{C}$; and one final step of $10 \mathrm{~min}$ at $72{ }^{\circ} \mathrm{C}$.

GISH or FISH images were recorded by use of an epifluorescence microscope (AxioImager A1, Carl Zeiss AG, Jena, Germany) equipped with a CoolSnap-fx CCD camera (Photometrics, Tucson, USA). Images were pseudo-colored, composed, and analyzed by use of Image-Pro Plus v5.0.2.9 (Media Cybenetics Inc., USA). Figures were edited by use of Adobe Photoshop 9.0 (Adobe Systems Inc., USA).

\section{Results}

The karyotype of the AR hybrids (Fig. 2) was established by the measurements of five complements (Table 2). On average, the total length of four M-type chromosomes was $41.61 \%$ of the length of all 18 chromosomes in a complement put together, the total length of three T-type chromosomes was $15.42 \%$, and the total length of 11 A-type chromosomes was $42.87 \%$ (Table 2). In a complement, the proportion of M- and T-type chromosomes $(57.03 \%)$ was more than that of A-type chromosomes.

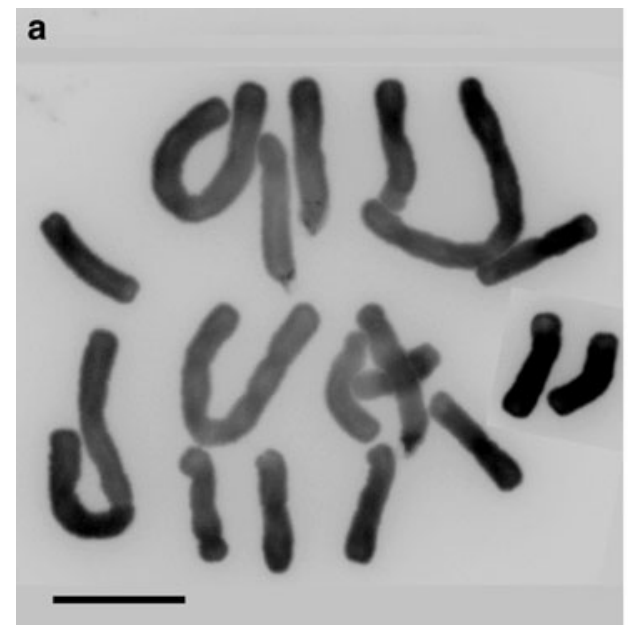

Fig. 2 The chromosome complement of F1 interspecific hybrid (AR, $2 n=18,4 \mathrm{M}+3 \mathrm{~T}+11 \mathrm{~A})$ of Lycoris aurea (LA, $2 n=14$, $8 \mathrm{M}+6 \mathrm{~T}$ ) and $L$. radiata $(\mathrm{LR}, 2 n=22,22 \mathrm{~A})$. The chromosome

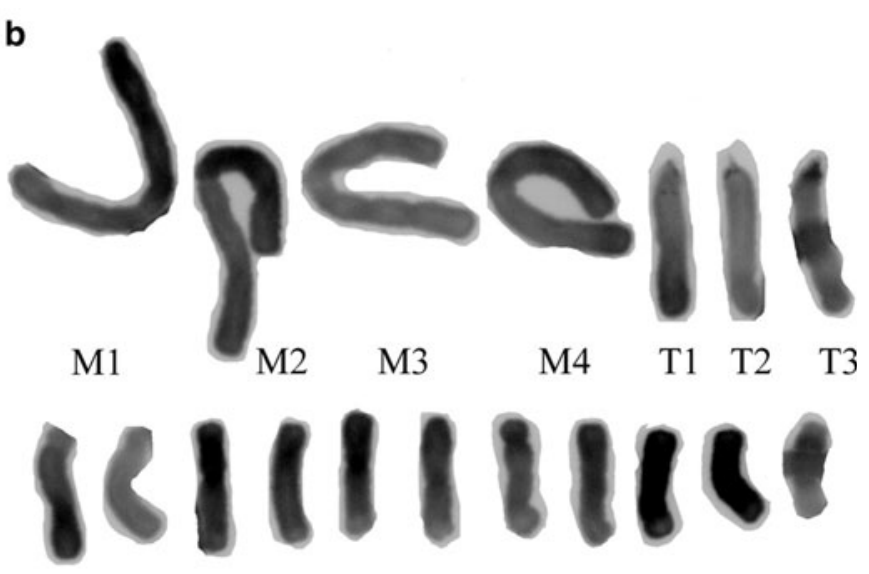

A1 A2 A3 A4 A5 A6 A7 A8 A9 A10 A11 complements in a were arranged according to their lengths in descending order in $\mathbf{b}$. Three types of chromosomes are metacentric (M), telocentric (T), and acrocentric (A). Bar $10 \mu \mathrm{m}$ 
Table 2 Relative length and arm ratio of chromosomes in a complement of F1 interspecific hybrids $\mathrm{AR}(2 n=4 \mathrm{M}+3 \mathrm{~T}+11 \mathrm{~A})$

\begin{tabular}{lccc}
\hline Chromosome $^{\mathrm{a}}$ & Relative length $(\%)^{\mathrm{b}}$ & ${\text { Arm ratio }(\mathrm{L} / \mathrm{S})^{\mathrm{c}}}^{\mathrm{s}}$ & Sum $^{\mathrm{d}}$ \\
\hline M1 & $11.18 \pm 0.43$ & $1.20 \pm 0.10$ & $41.61 \%$ \\
M2 & $10.64 \pm 0.24$ & $1.15 \pm 0.12$ & \\
M3 & $10.41 \pm 0.17$ & $1.15 \pm 0.06$ & \\
M4 & $9.38 \pm 0.54$ & $1.21 \pm 0.17$ & \\
T1 & $5.45 \pm 0.21$ & $11.66 \pm 3.21$ & $15.42 \%$ \\
T2 & $5.21 \pm 0.19$ & $12.70 \pm 3.60$ & \\
T3 & $4.76 \pm 0.50$ & $8.31 \pm 1.64$ & \\
A1 & $4.57 \pm 0.10$ & $4.55 \pm 1.61$ & $42.87 \%$ \\
A2 & $4.38 \pm 0.14$ & $6.12 \pm 1.00$ & \\
A3 & $4.24 \pm 0.16$ & $4.62 \pm 1.67$ & \\
A4 & $4.17 \pm 0.10$ & $5.50 \pm 1.99$ & \\
A5 & $4.06 \pm 0.13$ & $5.14 \pm 2.73$ & \\
A6 & $3.91 \pm 0.05$ & $4.41 \pm 1.88$ & \\
A7 & $3.84 \pm 0.07$ & $4.74 \pm 0.84$ & \\
A8 & $3.63 \pm 0.10$ & $3.57 \pm 1.10$ & \\
A9 & $3.53 \pm 0.18$ & $4.58 \pm 1.47$ & \\
A10 & $3.34 \pm 0.22$ & $3.56 \pm 0.52$ & \\
A11 & $3.20 \pm 0.20$ & $3.27 \pm 1.03$ & \\
\hline
\end{tabular}

${ }^{a}$ Based on the arm ratio, chromosomes are grouped into three types, including metacentrics (M), telocentrics (T), and acrocentrics (A) (Levan et al. 1964). Chromosomes are numbered according to their lengths in descending order within a group

${ }^{b}$ Relative length is the proportion of the absolute length of an individual chromosome to the total length of chromosomes in that complement. The absolute length $(\mu \mathrm{m})$ of each chromosomal arm was measured by use Image-Pro Plus software (V5.0.2.9, Media Cybenetics Inc., USA). The values of mean \pm standard deviation (SD) were calculated from five measurements

c Arm ratio = the length of the long arm (L)/the length of the short $\operatorname{arm}(\mathrm{S})$

${ }^{d}$ Sum is the proportion of the length of four M-type, three T-type, or eleven A-type chromosomes, respectively, in a complement

GISH revealed the chromosome composition of functional gametes recovered from the backcross progenies

GISH results revealed high homology between the genomes of $L$. aurea (MT-karyotype) and $L$. radiata (A-karyotype). When the total genomic DNA of $L$. radiata was used as a probe to perform GISH on chromosomes of L. aurea, GISH signals were spread over all chromosomes of $L$. aurea, but absent from the terminal region of each T-type chromosome (Fig. 3a). While the total genomic DNA of $L$. aurea was used as a probe to perform GISH on $L$. radiata, signals dispersed throughout every chromosome of $L$. radiata (Fig. $3 \mathrm{~b}$ ). When unlabeled blocking DNA in 60 -fold excess of probe DNA was added in the GISH mixture, chromosomes of $L$. radiata could be discriminated from those of $L$. aurea (Fig. 3c).
Besides, we detected the distribution of telomeric repeats on chromosomes by use of FISH with human-type telomeric repeats (TTAGGG) $n$ as probe to trace the possible occurrence of chromosome fusion. FISH signals of telomeric repeats were located at the distal end of every chromosomal arm, but none of the signals was detected at the intercalary region of Lycoris chromosomes (Fig. 4).

We performed GISH experiments on mitotic chromosomes of $34 \mathrm{BC} 1$ progenies, including $28 \mathrm{AAR}$, five RAR, and one SAR. These progenies have different chromosome numbers $(2 n=14-22)$ and complements as listed in Table 3. By GISH analyses, 23 of 34 progenies possessed recombinant chromosomes with different numbers and pattern, but the rest 11 plants lacked recombinant chromosomes. Actually, the chromosome complements of these 11 plants had been previously identified as one of their parental types by conventional staining (Wu et al. 2005), which are further confirmed by GISH results presented here. Among these 11 plants, four accessions (AAR103, AAR104-B, AAR107, and AAR201) were identical to $L$. aurea, six (AAR207-B, AAR213, AAR303, AAR305, AAR 510-A, and AAR 606) were identical to the AR hybrids, and RAR502 was identical to $L$. aurea (Table 3 ). These 11 accessions and one SAR (SAR301-B, $2 n=19$, $3 \mathrm{M}+2 \mathrm{~T}+14 \mathrm{~A}$ ) were excluded from later statistical recombination analyses.

GISH results demonstrate that these backcrossed progenies contained numerous recombinant chromosomes, indicating a high frequency of homoeologous recombination occurred at meiosis in the AR hybrids (Figs. 5, 6, 7; Table 3). The chromosome number of these progenies ranged from $2 n=14$ to $2 n=22$; some of the GISH results are shown as follows: $2 n=14$ (Fig. $5 \mathrm{a}-\mathrm{d}$ ), $2 n=15-18$ (Fig. 6a-d), $2 n=19-20 \quad$ (Fig. 7a-b), and $2 n=21$ (Fig. $7 \mathrm{c}-\mathrm{d}$ ). The origin of a recombinant chromosome is identified according to the fragment with centromere. The patterns of recombination are grouped into two types by the position of the exchanged fragment on that recombinant chromosome. A single recombinant chromosome has an exchanged fragment from another parental genome to join at the recombination site. A single recombinant chromosome appears as two connected segments with different GISH signals. A double recombinant chromosome has an exchanged segment from another parental genome inserted between two recombination sites. Thus, GISH results display a double recombinant chromosome as three connected segments, the intercalary one presents different GISH signals from both flanks (Fig. 5).

GISH results also provided cytological evidence to facilitate the identification of chromosome composition of the progeny. For example, it has been considered difficult to distinguish the complements of AAR404-A $(2 n=14$, $8 \mathrm{M}+5 \mathrm{~T}+1 \mathrm{~A})$ from that of $L$. aurea $(2 n=14$, 

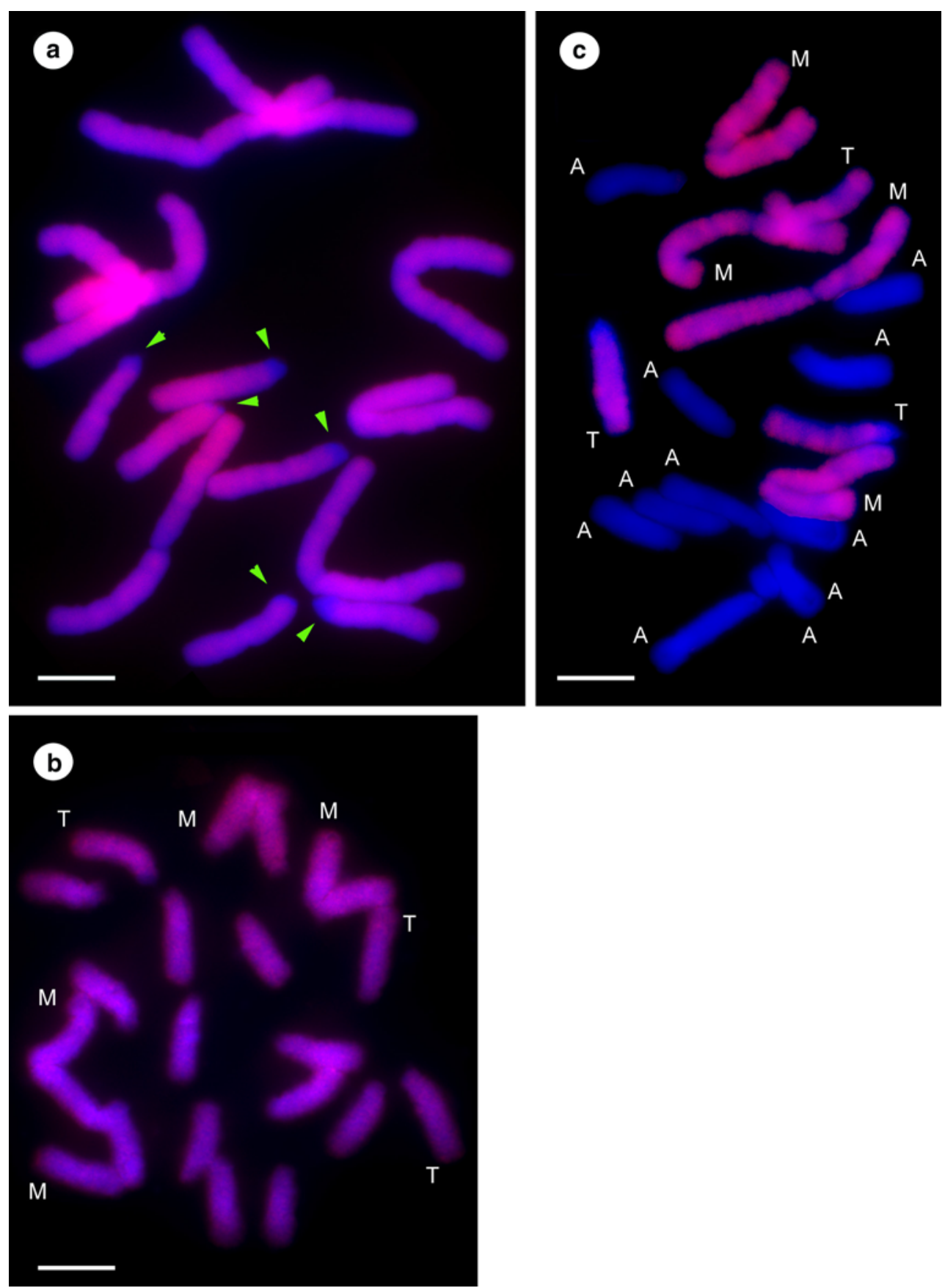

Fig. 3 The ability of genomic in situ hybridization (GISH) to discriminate chromosomes originated from different Lycoris genomes. a GISH signals (red) generated by total genomic DNA of $L$. radiata (A-karyotype) spread on all chromosomes of $L$. aurea (MTkaryotype), but were absent from the terminal region of each T-type chromosome (arrowheads). b GISH signals ( $r e d$ ) generated by total

$8 \mathrm{M}+6 \mathrm{~T})$ by conventional staining method because of the high similarity between A- and T-type chromosomes. GISH results indicated that the pollen which AAR404-A received from the $\mathrm{AR}$ hybrids was $4 \mathrm{M}+2 \mathrm{~T}+1 \mathrm{~A}$ instead of $4 \mathrm{M}+3 \mathrm{~T}$; moreover, that recovered pollen contained genomic DNA of $L$. aurea spread over all chromosomes of $L$. radiata. c In a complement of the AR hybrid, M- and T-type chromosomes (red) could be distinguished from A-type chromosomes (blue) by GISH with unlabeled genomic DNA of $L$. radiata added in 60-fold excess of probe DNA (L. aurea, red). Bar $10 \mu \mathrm{m}$

several recombinant chromosomes in its complement (Fig. 3a-b; Table 3). Similarly, the complement of AAR309 was revised from $2 n=14=8 \mathrm{M}+6 \mathrm{~T}$ (Wu et al. 2005) to $2 n=14=8 \mathrm{M}+5 \mathrm{~T}+1 \mathrm{~A}$ based on GISH results in this study (Fig. $5 \mathrm{c}-\mathrm{d})$. The complement which 


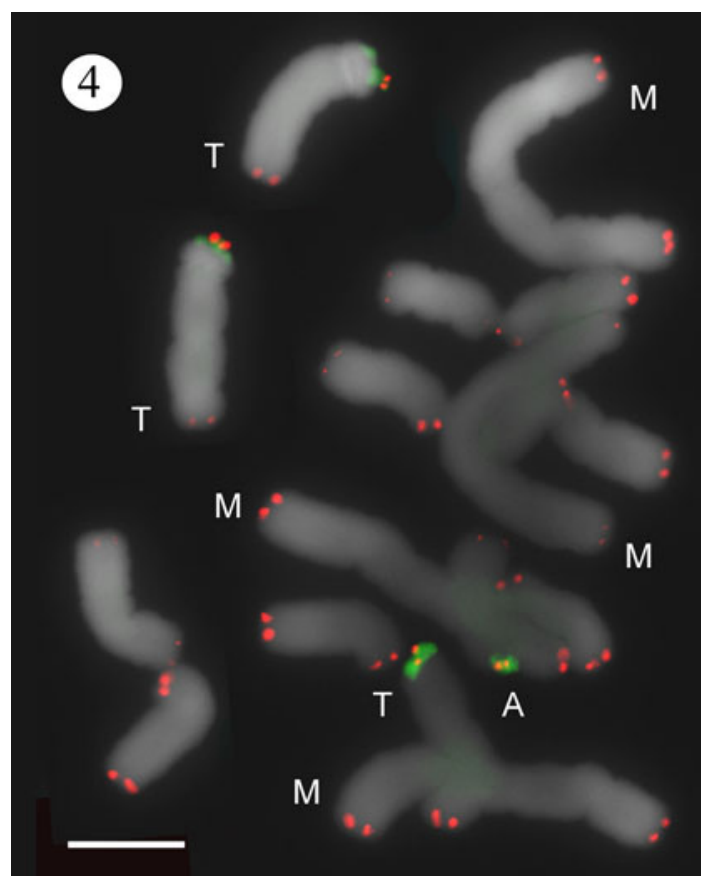

Fig. 4 The positions of telomeres on chromosomes detected in a complement of the AR hybrid. Human-type telomeric repeats (TTAGGG) $n$ were used as probe (red). Green signals indicate the positions of $45 \mathrm{~S}$ rDNA loci on 3 T-type and one A-type chromosomes. Bar $10 \mu \mathrm{m}$

donated by AR hybrid to AAR309 was $n=7=$ $4 \mathrm{M}+2 \mathrm{~T}+1 \mathrm{~A}$ with several recombinant chromosomes (Fig. 5c-d), including four single recombination (2 M-type, 1 T-type, and 1 A-type) and five double recombination (4 M-type and 1 T-type; Fig. 5d; Table 3). In the case of RAR913, its chromosome complement $(2 n=22$, 22A) was identical to that of $L$. aurea, but several recombinant fragments derived from the MT-type genome were detected (Table 3). Some of the recombination may lead to visible changes in chromosome morphologic features, such as shortened recombinant $\mathrm{M}$ - and T-type chromosomes in AAR404-A (Fig. 5b), shortened A-type chromosome in AAR309 (Fig. 5d), and extended recombinant A-type chromosome in RAR304 (Fig. 7d).

We have analyzed the GISH patterns on 226 chromosomes (64 M-type, 42 T-type, and 120 A-type) from recovered male gametes in $23 \mathrm{BC} 1$ (Table 3). Among these 226 chromosomes, 178 were recombinant chromosomes, including 98 chromosomes were single recombinants, 80 chromosomes were double recombinants; whereas the other 48 chromosomes are detected non-recombinants (Table 3). Among these recombinations, $29.77 \%$ were on M-type $(27+26=53), \quad 16.85 \%$ on T-type $(14+$ $16=30)$, and $53.37 \%$ on A-type $(57+38=95)$ chromosomes. Interestingly, the number of recombination on A-type chromosomes $(53.37 \%)$ was almost equal to the sum of that on M- and T-types chromosome. Since each M-type chromosome contains two major chromosome arms, the mean recombination per arm is half of $29.77 \%$ (i.e., $14.89 \%$ ), although less than that for T-type chromosomes, suggesting that each arm of M- and T-type chromosomes has similar opportunity to homoeologously pair and crossover with an A-type chromosome.

Recombination occurred throughout chromosomes but rarely in the pericentric region

We wondered whether recombination preferentially occurred in particular regions of Lycoris chromosomes. As summarized in Fig. 8, GISH results revealed various recombinant patterns on chromosomes of Lycoris. For standardized comparison of the positions of recombination on different chromosomes, each chromosome arm was equally divided into 100 units from centromere (0) to telomere (100). The distance between the centromere and the proximal end of each recombinant segment (L1) and the total length of that chromosome arm (L2) was measured. Then, the relative position of a recombination event was calculated as (L1/L2) $\times 100$ (Fig. 8). Only the main chromosome arms of A- and T-type chromosomes and two of M-type chromosomes were measured. All recombination fragments were found unevenly distributed along each chromosome arm of Lycoris (Fig. 8). In general, recombination sites often occurred at positions 60-90 (interstitial regions), a few at the proximal region (15-20), and distal end (90-100), but hardly in the pericentric region (0-15) of any type of chromosomes. Of note, recombination sites were mainly at positions $30-40$ and $60-80$ on A-type chromosomes (Fig. 8c).

\section{Discussion}

Homoeologous recombination in interspecific hybrid of Lycoris revealed by GISH

Interspecific hybridization and subsequent genetic modifications may change the chromosome number and structure rapidly, which has been acknowledged as an important mechanism of plant speciation (Soltis and Soltis 2009). In general, interspecific hybrids are mainly sterile because of disturbances in meiosis that may hamper chromosome pairing and genetic recombination, thus limiting the possibility of interspecific gene flow (Kopecky et al. 2010). However, interspecific hybrids, even with low fertility, are useful bridges in introgression breeding for gene transfer between different species. With the advent of molecular markers and GISH/FISH technologies, the extent and 
Table 3 The karyotypes and compositions of gametotypes in the test progenies of dikaryotype hybrids of spider lily detected by GISH analysis

\begin{tabular}{|c|c|c|c|c|c|c|c|}
\hline \multirow[t]{2}{*}{ Testprogenies $^{\mathrm{a}}$} & \multicolumn{2}{|c|}{ Chromosome $^{\mathrm{b}}$} & \multicolumn{2}{|c|}{ Male gametes ${ }^{c}$} & \multicolumn{3}{|c|}{ Number of recombinant fragment ${ }^{\mathrm{d}}$} \\
\hline & $2 n$ & Karyotypes & $n$ & Gametotypes & Single & Double & None \\
\hline AAR103 & 14 & $8 \mathrm{M}+6 \mathrm{~T}$ & 7 & $4 \mathrm{M}+3 \mathrm{~T}$ & 0 & 0 & - \\
\hline AAR104-B & 14 & $8 \mathrm{M}+6 \mathrm{~T}$ & 7 & $4 \mathrm{M}+3 \mathrm{~T}$ & 0 & 0 & - \\
\hline AAR107 & 14 & $8 \mathrm{M}+6 \mathrm{~T}$ & 7 & $4 \mathrm{M}+3 \mathrm{~T}$ & 0 & 0 & - \\
\hline AAR201 & 14 & $8 \mathrm{M}+6 \mathrm{~T}$ & 7 & $4 \mathrm{M}+3 \mathrm{~T}$ & 0 & 0 & - \\
\hline AAR309 & 14 & $8 \mathrm{M}+6 \mathrm{~T}$ & 7 & $4 \mathrm{M}+2 \mathrm{~T}+1 \mathrm{~A}^{-*}$ & $4(2 \mathrm{M}, 1 \mathrm{~T}, 1 \mathrm{~A})$ & $5(4 \mathrm{M}, 1 \mathrm{~T})$ & $1(1 \mathrm{M})$ \\
\hline AAR401-E & 14 & $8 \mathrm{M}+6 \mathrm{~T}$ & 7 & $4 \mathrm{M}+3 \mathrm{~T}$ & $2(2 \mathrm{M})$ & $2(2 \mathrm{M})$ & $5(2 \mathrm{M}, 3 \mathrm{~T})$ \\
\hline AAR402-A & 14 & $8 \mathrm{M}+6 \mathrm{~T}$ & 7 & $4 \mathrm{M}+3 \mathrm{~T}$ & $3(2 \mathrm{M}, 1 \mathrm{~T})$ & $1(1 \mathrm{M})$ & $4(2 \mathrm{M}, 2 \mathrm{~T})$ \\
\hline AAR404-A & 14 & $8 \mathrm{M}+5 \mathrm{~T}+1 \mathrm{~A}$ & 7 & $4 \mathrm{M}+2 \mathrm{~T}+1 \mathrm{~A}$ & $5(2 \mathrm{M}, 2 \mathrm{~T}, 1 \mathrm{~A})$ & $4(4 \mathrm{M})$ & $1(1 \mathrm{M})$ \\
\hline AAR203 & 15 & $7 \mathrm{M}+5 \mathrm{~T}+3 \mathrm{~A}$ & 8 & $3 \mathrm{M}+2 \mathrm{~T}+3 \mathrm{~A}$ & $3(2 \mathrm{M}, 1 \mathrm{~A})$ & $4(1 \mathrm{M}, 1 \mathrm{~T}, 2 \mathrm{~A})$ & $2(1 \mathrm{M}, 1 \mathrm{~T})$ \\
\hline AAR304 & 15 & $7 \mathrm{M}+5 \mathrm{~T}+3 \mathrm{~A}+1 \mathrm{M}$ & 8 & $3 \mathrm{M}+3 \mathrm{~T}+2 \mathrm{~A}^{*}$ & $5(2 \mathrm{M}, 2 \mathrm{~T}, 1 \mathrm{~A})$ & $5(4 \mathrm{M}, 1 \mathrm{~A})$ & $1(1 \mathrm{~T})$ \\
\hline AAR403-A & 15 & $7 \mathrm{M}+2 \mathrm{~T}+6 \mathrm{~A}$ & 8 & $3 \mathrm{M}+3 \mathrm{~T}+2 \mathrm{~A}^{*}$ & $6(4 \mathrm{M}, 1 \mathrm{~T}, 1 \mathrm{~A})$ & $2(1 \mathrm{M}, 1 \mathrm{~T})$ & $2(1 \mathrm{~T}, 1 \mathrm{~A})$ \\
\hline AAR610 & 15 & $7 \mathrm{M}+5 \mathrm{~T}+3 \mathrm{~A}$ & 8 & $3 \mathrm{M}+2 \mathrm{~T}+3 \mathrm{~A}$ & $5(2 \mathrm{M}, 1 \mathrm{~T}, 2 \mathrm{~A})$ & $5(2 \mathrm{M}, 2 \mathrm{~T}, 1 \mathrm{~A})$ & $1(1 \mathrm{M})$ \\
\hline AAR605-B & 16 & $6 \mathrm{M}+5 \mathrm{~T}+5 \mathrm{~A}$ & 9 & $2 \mathrm{M}+2 \mathrm{~T}+5 \mathrm{~A}$ & $5(2 \mathrm{M}, 1 \mathrm{~T}, 2 \mathrm{~A})$ & $6(1 \mathrm{M}, 1 \mathrm{~T}, 4 \mathrm{~A})$ & 0 \\
\hline AAR609 & 16 & $6 \mathrm{M}+4 \mathrm{~T}+6 \mathrm{~A}$ & 9 & $2 \mathrm{M}+1 \mathrm{~T}+6 \mathrm{~A}$ & $6(1 \mathrm{M}, 5 \mathrm{~A})$ & $4(2 \mathrm{M}, 1 \mathrm{~T}, 1 \mathrm{~A})$ & 0 \\
\hline AAR504-C & 16 & $6 \mathrm{M}+3 \mathrm{~T}+7 \mathrm{~A}$ & 9 & $2 \mathrm{M}+1 \mathrm{~T}+6 \mathrm{~A}^{*}$ & $2(2 \mathrm{~A})$ & $8(1 \mathrm{M}, 1 \mathrm{~T}, 6 \mathrm{~A})$ & $2(1 \mathrm{M}, 1 \mathrm{~A})$ \\
\hline AAR106-C & 17 & $5 \mathrm{M}+4 \mathrm{~T}+8 \mathrm{~A}$ & 10 & $1 \mathrm{M}+1 \mathrm{~T}+8 \mathrm{~A}$ & $5(1 \mathrm{M}, 1 \mathrm{~T}, 3 \mathrm{~A})$ & $2(2 \mathrm{~A})$ & $3(3 \mathrm{~A})$ \\
\hline AAR206 & 17 & $5 \mathrm{M}+4 \mathrm{~T}+8 \mathrm{~A}$ & 10 & $1 \mathrm{M}+1 \mathrm{~T}+8 \mathrm{~A}$ & $4(4 \mathrm{~A})$ & $4(1 \mathrm{M}, 3 \mathrm{~A})$ & $2(1 \mathrm{~T}, 1 \mathrm{~A})$ \\
\hline AAR306 & 17 & $5 \mathrm{M}+4 \mathrm{~T}+8 \mathrm{~A}$ & 10 & $1 \mathrm{M}+1 \mathrm{~T}+8 \mathrm{~A}$ & $6(1 \mathrm{M}, 5 \mathrm{~A})$ & $3(3 \mathrm{~A})$ & $2(1 \mathrm{~T}, 1 \mathrm{~A})$ \\
\hline AAR401-C & 17 & $5 \mathrm{M}+5 \mathrm{~T}+7 \mathrm{~A}$ & 10 & $1 \mathrm{M}+2 \mathrm{~T}+7 \mathrm{~A}$ & $3(1 \mathrm{~T}, 2 \mathrm{~A})$ & $7(1 \mathrm{M}, 1 \mathrm{~T}, 5 \mathrm{~A})$ & $1(1 \mathrm{~A})$ \\
\hline AAR602-A & 17 & $5 \mathrm{M}+5 \mathrm{~T}+7 \mathrm{~A}$ & 10 & $1 \mathrm{M}+3 \mathrm{~T}+6 \mathrm{~A}$ & $5(5 \mathrm{~A})$ & $5(1 \mathrm{M}, 2 \mathrm{~T}, 2 \mathrm{~A})$ & $2(1 \mathrm{~T}, 1 \mathrm{~A})$ \\
\hline AAR207-B & 18 & $4 \mathrm{M}+4 \mathrm{~T}+10 \mathrm{~A}+1 \mathrm{~A}^{-}$ & 11 & $11 \mathrm{~A} *$ & 0 & 0 & - \\
\hline AAR213 & 18 & $4 \mathrm{M}+3 \mathrm{~T}+11 \mathrm{~A}$ & 11 & $11 \mathrm{~A}$ & 0 & 0 & - \\
\hline AAR303 & 18 & $4 \mathrm{M}+3 \mathrm{~T}+11 \mathrm{~A}$ & 11 & $11 \mathrm{~A}$ & 0 & 0 & - \\
\hline AAR305 & 18 & $4 \mathrm{M}+3 \mathrm{~T}+11 \mathrm{~A}$ & 11 & $11 \mathrm{~A}$ & 0 & 0 & - \\
\hline AAR510-A & 18 & $4 \mathrm{M}+3 \mathrm{~T}+10 \mathrm{~A}+1 \mathrm{~A}^{-}$ & 11 & $11 \mathrm{~A}$ & 0 & 0 & - \\
\hline AAR606 & 18 & $4 \mathrm{M}+3 \mathrm{~T}+11 \mathrm{~A}$ & 11 & $11 \mathrm{~A}$ & 0 & 0 & - \\
\hline AAR307 & 18 & $4 \mathrm{M}+5 \mathrm{~T}+9 \mathrm{~A}$ & 11 & $2 \mathrm{~T}+9 \mathrm{~A}$ & $2(2 \mathrm{~A})$ & $5(3 \mathrm{~T}, 2 \mathrm{~A})$ & $5(5 \mathrm{~A})$ \\
\hline AAR408 & 18 & $4 \mathrm{M}+5 \mathrm{~T}+9 \mathrm{~A}$ & 11 & $2 \mathrm{~T}+9 \mathrm{~A}$ & $5(1 \mathrm{~T}, 4 \mathrm{~A})$ & $1(1 \mathrm{~A})$ & $5(1 \mathrm{~T}, 4 \mathrm{~A})$ \\
\hline RAR201 & 19 & $3 \mathrm{M}+2 \mathrm{~T}+14 \mathrm{~A}$ & 8 & $3 \mathrm{M}+2 \mathrm{~T}+3 \mathrm{~A}$ & $4(2 \mathrm{M}, 1 \mathrm{~T}, 1 \mathrm{~A})$ & $2(1 \mathrm{~T}, 1 \mathrm{~A})$ & $2(1 \mathrm{M}, 1 \mathrm{~A})$ \\
\hline RAR301-A & 20 & $2 \mathrm{M}+1 \mathrm{~T}+17 \mathrm{~A}$ & 9 & $2 \mathrm{M}+1 \mathrm{~T}+6 \mathrm{~A}$ & $7(1 \mathrm{M}, 1 \mathrm{~T}, 5 \mathrm{~A})$ & $2(1 \mathrm{~T}, 1 \mathrm{~A})$ & $1(1 \mathrm{M})$ \\
\hline RAR304 & 21 & $1 \mathrm{M}+1 \mathrm{~T}+19 \mathrm{~A}$ & 10 & $1 \mathrm{M}+9 \mathrm{~A} *$ & $6(1 \mathrm{M}, 5 \mathrm{~A})$ & 0 & $3(3 \mathrm{~A})$ \\
\hline RAR913 & 22 & $22 \mathrm{~A}$ & 11 & $11 \mathrm{~A}$ & $5(5 \mathrm{~A})$ & $3(3 \mathrm{~A})$ & $3(3 \mathrm{~A})$ \\
\hline \multirow[t]{2}{*}{ RAR502 } & 22 & $2 \mathrm{~T}+20 \mathrm{~A}$ & 11 & $11 \mathrm{~A}$ & 0 & 0 & - \\
\hline & & & & & $98(27 \mathrm{M}, 14 \mathrm{~T}, 57 \mathrm{~A})$ & $80(26 \mathrm{M}, 16 \mathrm{~T}, 38 \mathrm{~A})$ & $48(11 \mathrm{M}, 12 \mathrm{~T}, 25 \mathrm{~A})$ \\
\hline
\end{tabular}

${ }^{a}$ The name and parentage of these accessions are identical to as that in Table 1 . The first letter represents the tester parent. A $=$ Lycoris aurea $(2 n=14$, $8 \mathrm{M}+6 \mathrm{~T}) ; \mathrm{R}=$ L. radiata $(2 n=22,22 \mathrm{~A})$. The second and third letters represent both parents of $\mathrm{F} 1$ interspecific hybrids AR. Numbers indicate individual plants derived from the same backcross

b The chromosome number $(n)$ and composition of each accession was previously identified by staining method (Wu et al. 2005). $M$ metacentric chromosome, $T$ telocentric chromosome, $A$ acrocentric chromosome, $m$ metacentric chromosome in obviously small size, $\mathrm{A}^{-}$acrocentric chromosome in obviously small size

c The male gametes contributed by the AR hybrids. The chromosome number $(n)$ and composition of each accession was previously identified by staining method (Wu et al. 2005). The asterisk (*) indicates that the gametotype has been revised according to the GISH results provided here

d The total number of chromosomes detected by GISH in each accession to contain single recombinant (single), double recombinant (double), or none recombination (none)

pattern of homoeologous recombination and the amount of introgression have been studied in diverse groups of plants (for review see Benavente et al. 2008). Among those achievements, the production of Festuloliums (Festuca $\times$ Lolium hybrids) are the most well-known and successful (Kopecky et al. 2008). 

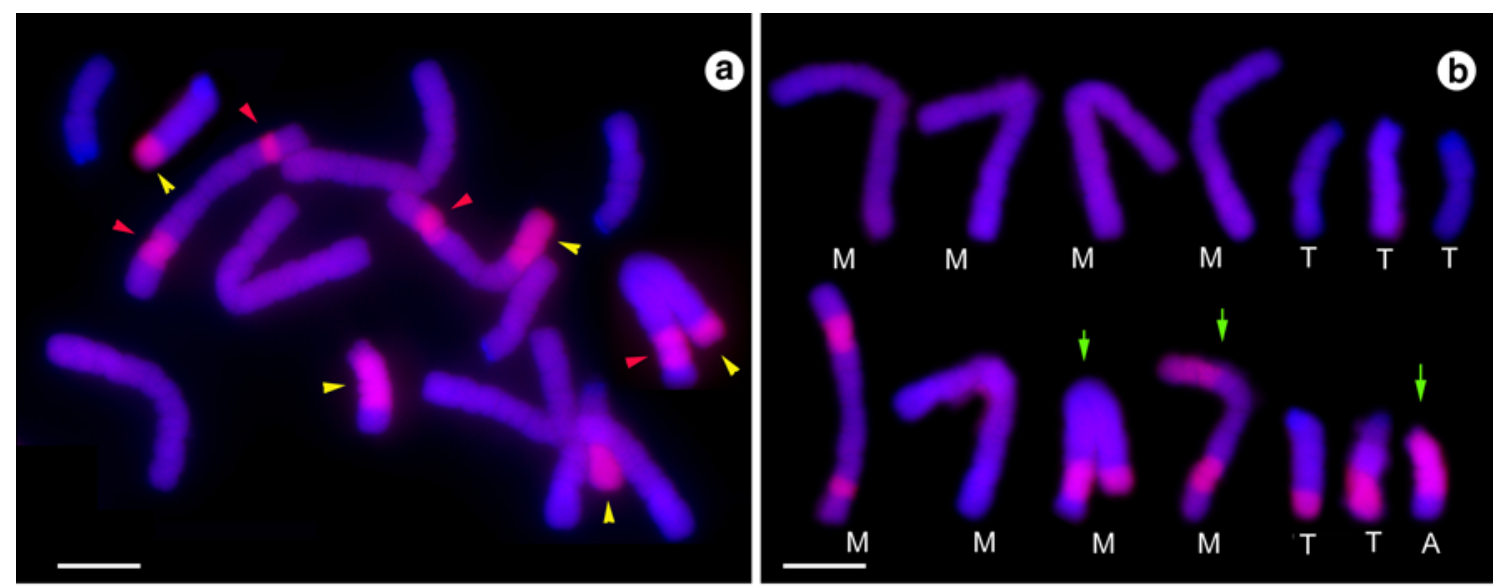

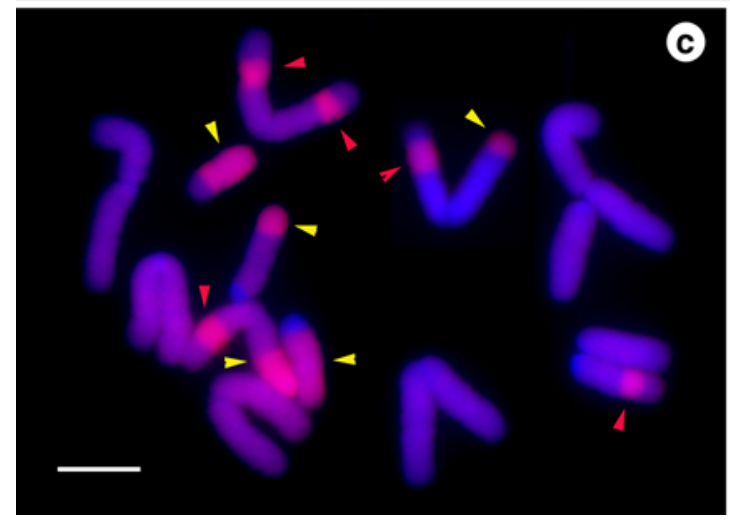

Fig. 5 Recombinant chromosomes of $\mathrm{BC} 1$ progenies with $2 n=14$ revealed by GISH with blocking DNA. The genomic DNA of $L$. radiata (A-karyotype) was used as a probe in following experiments. Red signals indicate chromosome segments derived from the genome used for probe. The origin of a recombinant chromosome is identified according to the fragment with centromere. A single recombinant chromosome is composed of two segments with different GISH labeled (yellow arrowhead). A double recombinant chromosome (red arrowhead) is composed of three segments, intercalary one is labeled

Meiosis of AR hybrids could reproduce functional pollens with different chromosome numbers $(n=7-11)$ and compositions, which responded to the variations of the karyotypes among these $\mathrm{BC} 1$ progenies (Table 3). Interestingly, the total numbers of chromosomal arm of these functional pollens recovered from $\mathrm{BC} 1$ progenies are constant as a multiple of $11(\mathrm{NF}=11)$. Some of the $\mathrm{BC} 1$ progenies with chromosome number $2 n=25-27$ were identified as triploid ( $\mathrm{NF}=33$ ) (Wu et al. 2005). In this study, GISH revealed a high homology between $L$. aurea (MT-karyotype) and L. radiata (A-karyotype) (Fig. 3a-c), which may explain the frequent occurrence of homoeologous pairing between both parental genomes in AR hybrids. However, GISH enabled distinguished both genomes by adding a suitable amount of the blocking DNA (Figs. 3c, 5, 6, 7), which indicates that considerable divergence existed between the MT-karyotype and the A-karyotype genome. The ability of GISH to distinguish

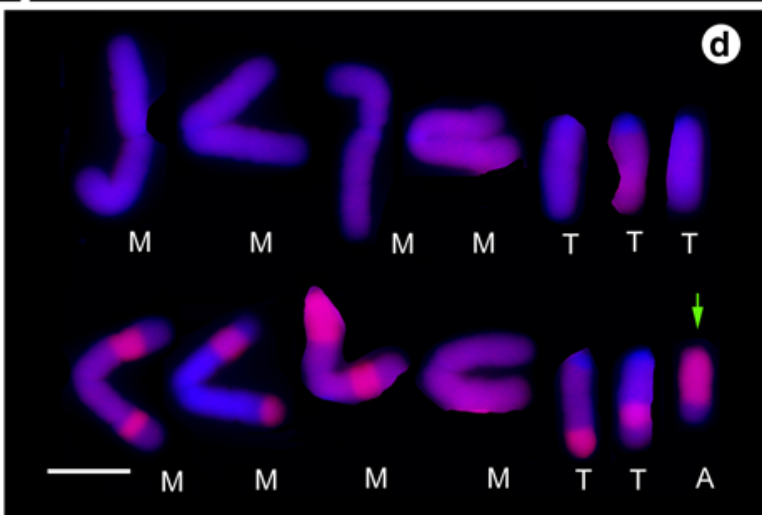

with different GISH signals from the other two segments at both flanks. Arrows indicate the chromosomes which were obviously shortened due to recombination. a, b AAR404A $(2 n=14$, $8 \mathrm{M}+5 \mathrm{~T}+1 \mathrm{~A})$ and $\mathbf{c}$, d AAR309 $(2 n=14,8 \mathrm{M}+5 \mathrm{~T}+1 \mathrm{~A})$. The chromosome complements in a, c were arranged in $\mathbf{b}, \mathbf{d}$, respectively, according to their lengths in descending order. Upper chromosomes from the female parent; Lower chromosomes of pollens of the AR hybrid. Bar $10 \mu \mathrm{m}$

closely related genomes at chromosomal levels depends on the diverse repetitive sequences in both genomes. Repetitive sequences in related genomes may be diverse in type and number as well as their organization and distribution at chromosome level (Anamthawat-Jonsson and Reader 1995; Lee et al. 2011). Therefore, partial fertility and frequent homoeologous pairing and recombination in AR hybrids may cause genomic divergence among Lycoris taxa, which provoked specification in the genus Lycoris.

Possible configuration of homoeologous pairing between M-, T-, and A-type chromosomes

In plants, chromosome pairing and crossover can be established when DNA sequence similarity and the length of homology are available and the genetic systems for controlling the pairing stringency are absent (Shen and Huang 1986; Sant'Angelo et al. 1992; Datta et al. 1997). 

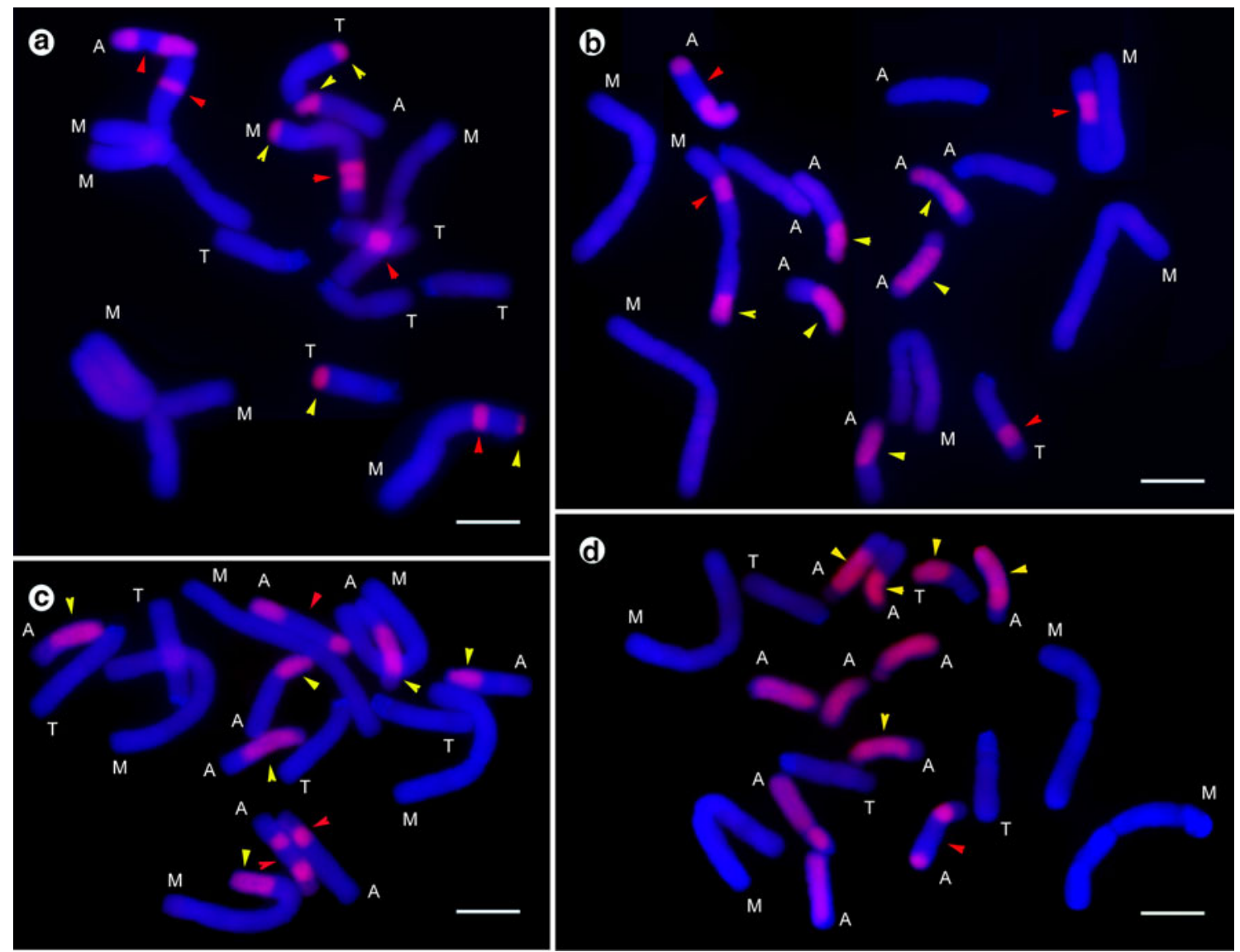

Fig. 6 Recombinant chromosomes of $\mathrm{BC} 1$ progenies with $2 n=15-18$ revealed by GISH with blocking DNA. The genomic DNA of $L$. radiata (A-karyotype) was used as a probe in following

Homoeologous chromosomes are chromosomes in related species possessing similar morphologic features, structure, and gene loci. However, homoeologous chromosomes may be highly differentiated because numerous alterations in DNA composition and genomic organization would be accumulated through evolution (Armstrong and Keller 1982). Therefore, homoeologous chromosome pairing at meiosis of an F1 interspecific hybrid interprets the affinity between both parental genomes (Lee et al. 2011).

As mentioned above, the studies on meiosis of Lycoris are restrained due to inconvenience in sample collection. In limited reports, different pairing configurations have been observed in Lycoris with M-T-A karyotypes. All together, these investigations indicated high homology between M- and A-type chromosomes, also suggested a fusion or fission relationship between these two types of chromosomes (Inariyama 1932; Koyama 1962, 1978). However, the evolutionary connection between the T-type chromosomes and the other two types remains unknown (Jones 1998). Our GISH analysis revealed that the recombinant segments on A-type chromosomes $(53.37 \%)$ is roughly close to the total of recombinant segments on T-type $(16.85 \%)$ and experiments. a AAR304 $(2 n=15,7 \mathrm{M}+6 \mathrm{~T}+2 \mathrm{~A})$, b AAR 609 $(2 n=16,6 \mathrm{M}+4 \mathrm{~T}+6 \mathrm{~A}), \mathbf{c}$ AAR306 $(2 n=17,5 \mathrm{M}+4 \mathrm{~T}+8 \mathrm{~A})$, d AAR408 $(2 n=18,4 \mathrm{M}+5 \mathrm{~T}+9 \mathrm{~A})$. Bar $10 \mu \mathrm{m}$

M-type chromosomes (29.77\%) (Table 3), which strongly supports that in a AR hybrid each A-type chromosome derived from $L$. radiata (11A) would associate with its corresponding chromosomal arm of $\mathrm{M}$ - or T-type chromosomes derived from $L$. aurea $(4 \mathrm{M}+3 \mathrm{~T})$. In other words, the most promising chromosome association at meiosis of AR hybrids $(2 n=18,4 \mathrm{M}+3 \mathrm{~T}+11 \mathrm{~A})$ is a configuration of 4 III (M-2A) +3 II (T-A). Theoretically, the gametes produced by balanced segregation of the configuration [4III (M-2A) + 3II (T-A)] would possess $2^{7}=128$ types of chromosome complements, including MA and T-A types which were not found in natural Lycoris taxa (Yuan et al. 1998). The high homology between the MT- and TA-karyotype genome (Fig. 3a-b) suggests that MA- or TA-karyotype genomes are absent in nature because of the existence of incompletion, duplication, and imbalance between $\mathrm{M}$ - and A-genomes, as well as between $\mathrm{T}$ - and A-genomes.

Although the molecular nature of regions with an unusually high or low frequency of homoeologous recombination is unclear (Akhunov et al. 2003; Mézard 2006), increasing GISH data has revealed that chromosomal 

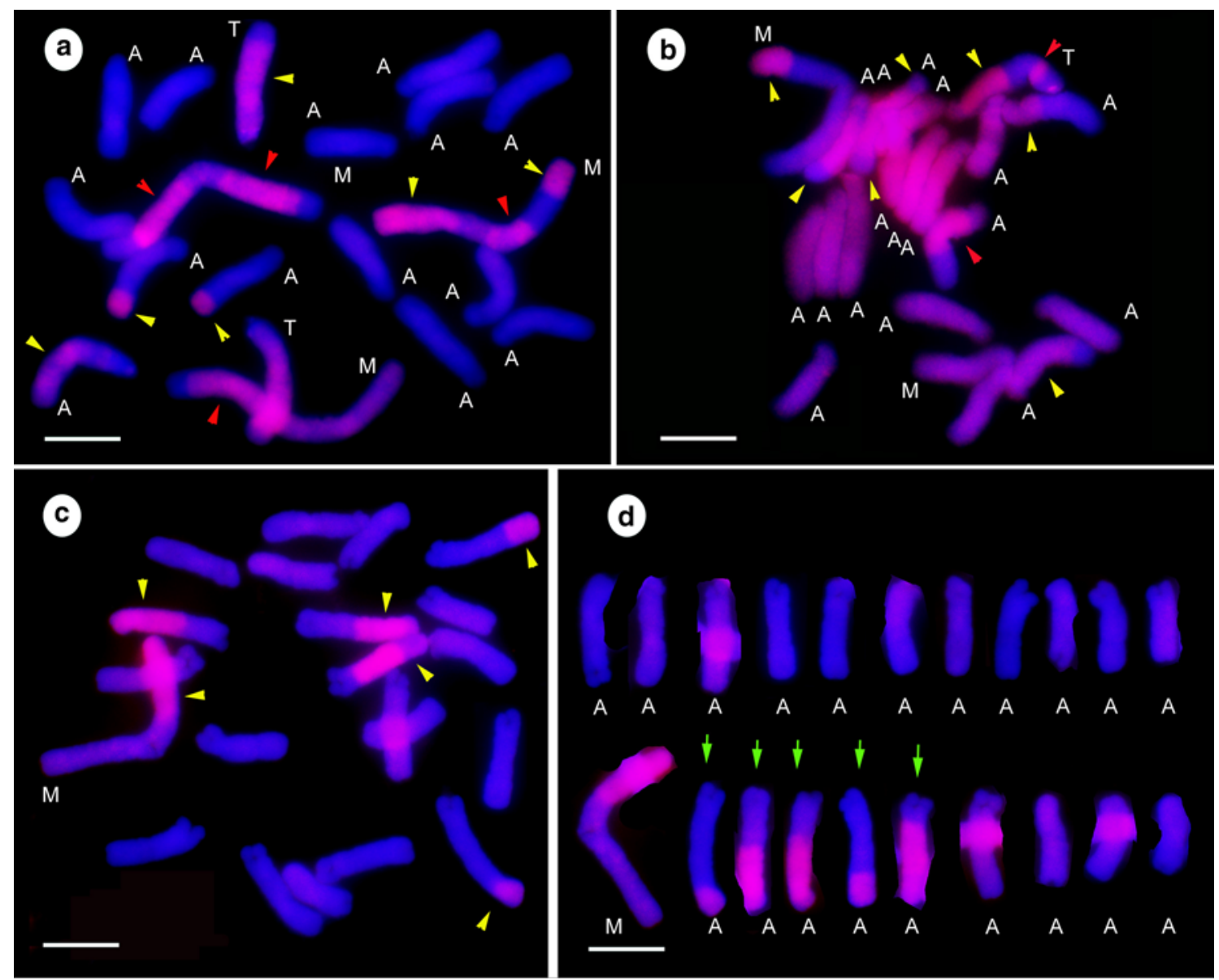

Fig. 7 Recombinant chromosomes of $\mathrm{BC} 1$ progenies with $2 n=19-21$ revealed by GISH with blocking DNA. a SAR301-B $(2 n=19,3 \mathrm{M}+2 \mathrm{~T}+14 \mathrm{~A})$, probe: $L$. aurea (MT-karyotype), b RAR301A $(2 n=20,2 \mathrm{M}+1 \mathrm{~T}+17 \mathrm{~A})$, probe: $L$. radiata (A-karyotype). c, d RAR304 $(2 n=21,1 \mathrm{M}+1 \mathrm{~T}+19 \mathrm{~A})$, probe:

recombination commonly occurred in interspecific hybrids. Homoeologous recombination events were frequently detected in interspecific hybrids of Lilium (Karlov et al. 1999) and in hybrids of Tulipa (Marasek-Ciolakowska et al. 2012). Lycoris is similar to both Lilium and Tulipa in several biological features, for example, being cultivated as bulbous ornamental crops and possessing large chromosomes (Bennett 1972; Zonneveld 2009; this study). However, GISH analyses revealed different recombination patterns on these plants. GISH results displayed one or two recombinant segments per chromosome in progenies of interspecific hybrids of tulips (Marasek-Ciolakowska et al. 2012); while more than two recombinant segments were detected per chromosome of Lilium (Khan et al. 2009). Crossover occurred randomly along all chromosomes of tulips, but was restricted to particular chromosomes of Lilium (Khan et al. 2009; Marasek-Ciolakowska et al. 2012). Chromosomal recombination maps for three Lilium genomes have been constructed based on recombination sites accurately
L. aurea (MT-karyotype). Chromosome complements in $\mathbf{c}$ were arranged according to their lengths in descending order in d. Upper chromosomes from female parent ( $L$. radiata, $n=11,11 \mathrm{~A})$; lower chromosomes of pollens of the AR hybrid. Arrows indicate chromosomes obviously extended due to recombination. Bar $10 \mu \mathrm{m}$

identified by GISH of chromosomes of the BC progenies of interspecific hybrids (Khan et al. 2009). Recombination sites were detected along the length of three types of chromosomes of Lycoris (Fig. 8). In general, the recombination sites were mainly in the interstitial positions (position 60-90) on each chromosomal arm, less in the telomeric/subtelomeric positions $(>90)$, or in pericentromeric regions (20-30), but rarely near the centromere $(<10)$. Interestingly, two recombination "hot-spot" regions are at positions 30-40 and 60-80 on A-type chromosomes (Fig. 8). Except for the A-type chromosomes, such distribution of recombination on Lycoris chromosomes is similar to previous observations in most organisms (for references, see Kopecky et al. 2010).

Interspecific hybridization and karyotype evolutionary in Lycoris

Although several mechanisms have been recognized to account for the variations in karyotypes among related 


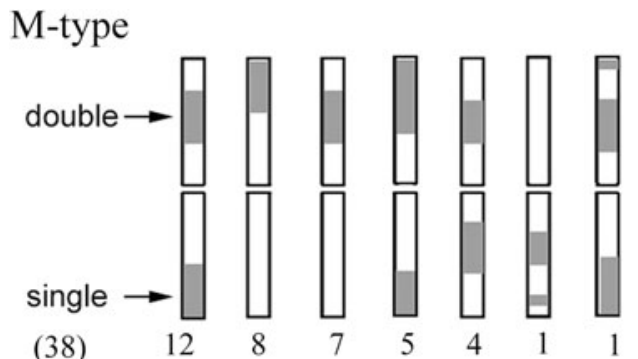

T-type

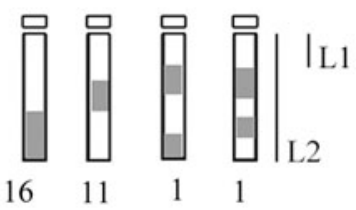

Fig. 8 Summary of the patterns and distribution of recombination on three types of chromosomes of Lycoris. Each chromosome arm is equally divided into 100 units from the centromere $(0)$ to telomere (100). The relative site of a recombination is calculated as (L1/

species, the history of karyotype evolution is often complex and puzzling. Recently, an integrated approach with comparative genetics, genomic analyses, and comparative chromosome painting has facilitated extended studies of karyotype evolution in mammals and plants such as Brassicaceae (for review, see Schubert and Lysak 2011). The karyotype evolution and phylogenetic relationship within Lycoris has been studied and discussed on the basis of cytological observations for decades (for review, see Kurita 1988; Jones 1998). However, studies of the karyotype evolution of Lycoris by comparative genetics and genomic analyses are still limited because of less knowledge of the genetic background and genomic DNA sequence data of Lycoris.

Based on cytological investigations, two major hypotheses have been considered for karyotype evolution in
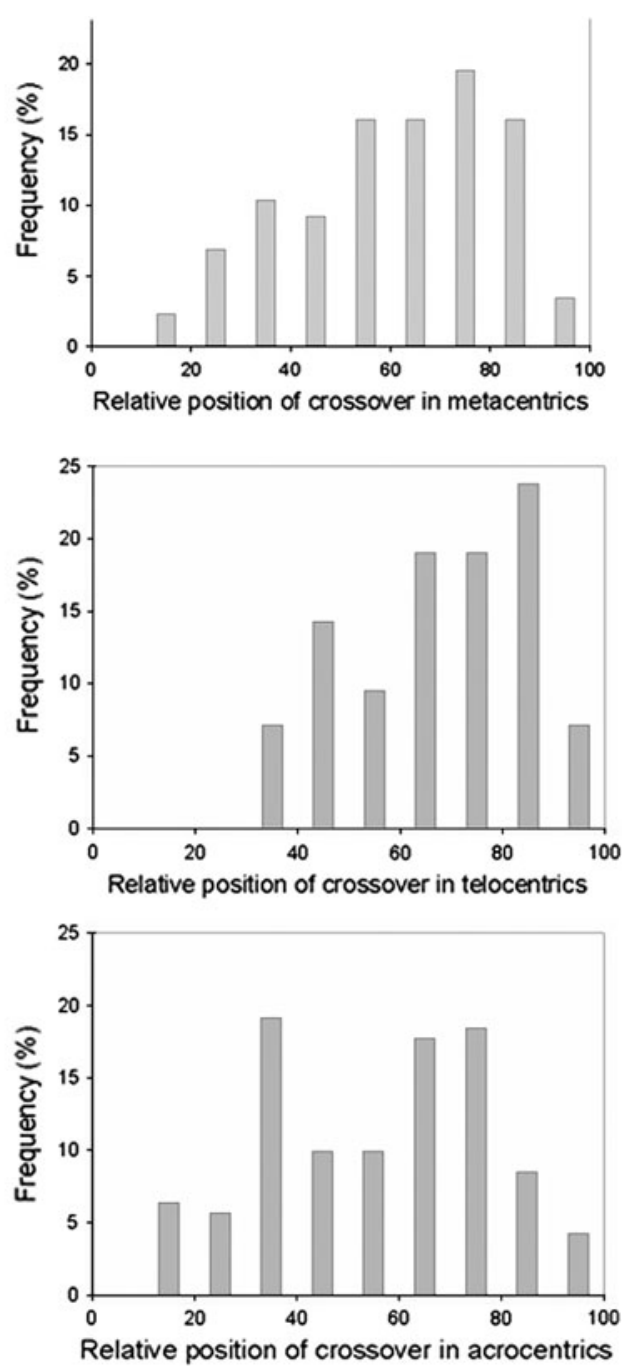

L2) $\times 100$. The number indicates the count of each pattern. The number in parenthesis indicates the count of measurements of each type of chromosome. The arrows indicate two types of recombination, single and double

Lycoris. The fission hypothesis suggested that an M-type chromosome would make two T-type chromosomes through centromeric fission (Darlington 1963; Flory 1977). The fusion hypothesis proposed A-karyotype species $(2 n=22,22 \mathrm{~A})$ as the ancestral type in Lycoris. Thus, a fusion occurs between two A-type chromosomes to make an M-type chromosome (Inariyama 1951a, b; Jones 1978; Nishikawa et al. 1979). A-type chromosome may become T-type chromosome simply by pericentric inversion, which has been observed in L straminea and in L. aurea (Kurita 1987). Recently, the development of molecular markers (isozyme and DNA-based markers) and advent cytogenetic methods (FISH and GISH) allows investigating the phylogenetic relationships among Lycoris species (for review, see Tarumoto et al. 2006). The fusion hypothesis was supported by the phylogenetic analysis of chloroplast 
genome sequences, which suggested Lycoris radiata var. pumila $(2 n=22 \mathrm{~A})$ as an ancestral taxon of Lycoris (Hori et al. 2006). However, the fusion hypothesis failed to explain why the total length of M- and T-type chromosomes are always longer than A-type chromosomes in some putative hybrid taxa (Kurita 1988) and in our artificial AR hybrids (Table 2). The T-type chromosome is less possible to be the ancestral type in Lycoris because none Lycoris taxa with a pure T-type chromosome in its complement has been found in their natural habitat and the formation of an M-type chromosome by two T-type chromosomes was never observed (Kurita 1987, 1988).

Our results present in this study and in previous report (Chang et al. 2009) support the fission hypothesis for karyotype evolution in Lycoris. First, no telomeric repeats were detected at the intercalary region on Lycoris chromosomes (Fig. 4). Since the existence of interstitial telomeric sequence has been considered as a visible trace of chromosome fusion (Biessman and Mason 1994; Fuchs et al. 1995; Bolzan and Bianchi 2006), the fusion hypothesis seems less acceptable in this case. Second, the measurement of chromosome length (Table 2) and the GISH results (Fig. 3a) indicated that the genome content of MTkaryotype is more than that of A-karyotype. GISH signals from genomic DNA of $L$. radiata (A-karyotype) were absent from the terminal region of each T-type chromosome of L. aurea (MT-karyotype) (Fig. 3a), suggesting these regions comprised nova DNA sequences that are absent in the A-karyotype genome. As we reported previously, the terminal region of each T-type chromosome stained positive with DAPI and contained abundant $5 \mathrm{~S}$ rDNAs and 45SrDNAs repeats (Chang et al. 2009). Various and abundant repetitive sequences were amplified and added to the broken chromosomal ends due to the centromeric fission occurred at a M-type chromosome for stabilizing two newly formed T-type chromosomes (Jones 1998).

Secondarily structural rearrangements following centromeric fission may have been involved in the chromosome re-patterning in Lycoris, which may be provoked by frequent interspecific hybridization occurred in their natural habitat. For example, some other types of chromosomes, such as M', T', a, and m, were observed in addition to the three major types in putative hybrid taxa of Lycoris (Kurita 1987, 1988; Figs. 5b, d, 7d in this study), which suggests a common occurrence of chromosome morphologic changes in interspecific hybrids. Rapid karyotype changes invoked by interspecific hybridization may facilitate the development of reproductive isolation between a hybrid lineage and parents, and then promote the formation of a new species (hybrid speciation) (Rieseberg 1997; Gross and Rieseberg 2005; Howarth and Baum 2005; Mir et al. 2006).
Concluding remarks

The MT- and A-karyotype genomes of Lycoris are high homology which accounts for high frequency of homoeologous recombination in F1 interspecific hybrids of $L$. aurea $($ MT-karyotype) $\times$ L. radiata (A-karyotype). On the other hand, the MT-type chromosomes could be discriminated from A-type chromosomes by GISH with blocking DNA, which demonstrates the existence of considerable divergence between both genomes at chromosomal level. Interspecific hybrids presented partial fertility, and homoeologous recombination played important roles in driving divergence and specification in Lycoris. However, more evidence and more molecular markers are needed to elucidate the karyotype evolution of the Lycoris.

Acknowledgments This work was supported by Institute of Plant and Microbial Biology, Academia Sinica, Taiwan, ROC and National Science Council, Taiwan, ROC [NSC 99-2321-B-001-037].

Open Access This article is distributed under the terms of the Creative Commons Attribution License which permits any use, distribution, and reproduction in any medium, provided the original author(s) and the source are credited.

\section{References}

Akhunov ED, Akhunova AR, Linkiewicz AM et al (2003) Synteny perturbations between wheat homoeologous chromosomes caused by locus duplications and deletions correlate with recombination rates. Proc Natl Acad Sci USA 100:10836-10841

Anamthawat-Jonsson K, Reader SM (1995) Preannealing of total genomic DNA probes for simultaneous genomic in situ hybridization. Genome 38:814-816

Anamthawat-Jonsson K, Schwarzacher T, Leitch AR, Bennett MD, Heslop-Harrison JS (1990) Discrimination between closely related Triticeae species using genomic DNA as a probe. Theor Appl Genet 79:721-728

Armstrong KC, Keller WA (1982) Chromosome pairing in haploids of Brassica oleracea. Can J Genet Cytol 24:735-739

Benavente E, Cifuentes M, Dusautoir JC, David J (2008) The use of cytogenetic tools for studies in the crop-to-wild gene transfer scenario. Cytogenet Genome Res 120:384-395

Bennett MD (1972) Nuclear DNA content and minimum generation time in herbaceous plants. Proc R Soc Lond B Biol Sci 181:109-135

Biessman H, Mason JM (1994) Telomeric repeat sequences. Chromosoma 103:154-161

Bolzan AD, Bianchi MS (2006) Telomeres, interstitial telomeric repeat sequences, and chromosomal aberrations. Mutat Res 612:189-214

Chang YC, Shii CT, Chung MC (2009) Variations in ribosomal RNA gene loci in spider lily (Lycoris spp.). J Am Soc Hort Sci 134:567-573

Chung MG (1999) Notes on allozyme variation in Lycoris radiata (Amaryllidaceae) from Korea. Bot Bull Acad Sinica 40:227-230

Chung MC, Lee YI, Cheng YY, Chou YJ, Lu CF (2008) Chromosomal polymorphism of ribosomal genes in the genus Oryza. Theor Appl Genet 116:745-753 
Dafni A, Shmida A, Aviohai M (1981) Leafless autumnal-flowering geophytes in the Mediterranean region; Phytogeographical, ecological and evolutionary aspect. Plant Syst Evol 137:181-193

Darlington CD (1963) Chromosome botany and origin of cultivated plants. Hafner Publ Co., London

Datta A, Hendrix M, Lipsitch M, Jinks-Robertson S (1997) Dual roles for DNA sequence identity and the mismatch repair system in the regulation of mitotic crossing over in yeast. Proc Natl Acad Sci USA 94:9757-9762

Flory WS (1977) Overview of chromosome evolution in the Amaryllidaceae. Nucleus 20:70-88

Fuchs J, Brandes A, Schubert I (1995) Telomere sequence localization and karyotype evolution in higher plants. Plant Syst Evol 196:227-241

Gawel NJ, Jarret RL (1991) A modified CTAB DNA extraction procedure for Musa and Ipomoea. Plant Mol Biol Rep 9:292-296

Gross BL, Rieseberg LH (2005) The ecological genetics of homoploid hybrid speciation. J Hered 96:241-252

Guerra M (2008) Chromosome numbers in plant cytotaxonomy: concepts and implications. Cytogenet Genome Res 120:339-350

Hayashi A, Saito T, Mukai Y, Kurita S, Hori T (2005) Genetic variations in Lycoris radiata var. radiata in Japan. Genes Genet Syst 80:199-212

Hori T, Hayashi A, Sasanuma T, Kurita S (2006) Genetic variations in the chloroplast genome and phylogenetic clustering of Lycoris species. Genes Genet Syst 81:243-253

Howarth DG, Baum DA (2005) Genealogical evidence of homoploid hybrid speciation in an adaptive radiation of Scaevola (Goodeniaceae) in the Hawaiian Islands. Evolution 59:948-961

Hsu PS, Kurita S, Yu ZZ, Lin JZ (1994) Synopsis of the genus Lycoris (Amaryllidaceae). Sida 16:301-331

Ijdo LW, Wells RA, Baldini A, Reeders ST (1991) Improved telomere detection using a telomere repeat probe (TTAGGG) $n$ generated by PCR. Nucleic Acids Res 19:4780

Inariyama S (1932) Cytological studies of the genus Lycoris 1. Conjugation of chromosomes in meiosis in L. albiflora Koidz. Bot Mag Tokyo 46:426-434

Inariyama S (1951a) Cytological studies in the genus Lycoris (I). Sci Rep Tokyo Bunrika Daigaku Sec B 6:74-100

Inariyama $\mathrm{S}$ (1951b) Cytological studies in the genus Lycoris (II). Sci Rep Tokyo Bunrika Daigaku Sec B 7:103-157

Jones K (1978) Aspects of chromosome evolution in higher plants. Recent Adv Bot 6:119-194

Jones K (1998) Robertsonian fusion and centric fission in karyotype evolution of higher plants. Bot Rev 64:273-289

Karlov GI, Khrustaleva LI, Lim KB, Van Tuyl JM (1999) Homoeologous recombination in $2 n$-gametes producing interspecific hybrids of Lilium (Liliaceae) studied by genomic in situ hybridization (GISH). Genome 42:681-686

Khan N, Barba-Gonzalez R, Ramanna MS, Visser RGF, Van Tuyl JM (2009) Construction of chromosomal recombination maps of three genomes of lilies (Lilium) based on GISH analysis. Genome 52:238-251

Kopecky D, Lukaszewski AJ, Doležel J (2008) Cytogenetics of Festulolium (Festuca $\times$ Lolium hybrids). Cytogenet Genome Res 120:370-383

Kopecky D, Havrankova M, Loureiro J et al (2010) Physical distribution of homoeologous recombination in individual chromosomes of Festuca pratensis in Lolium multiflorum. Cytogenet Genome Res 129:162-172

Koyama M (1962) Meiosis in Lycoris albiflora. Ann Rep Doshisha Women's College 12:9-12

Koyama M (1978) Chromosome pairing in the genus Lycoris II. Ann Rep Doshisha Women's College 29:272-282
Kurita S (1986) Variation and evolution in the karyotype of Lycoris, Amaryllidaceae. 1. General karyomorphological characteristics of the genus. Cytologia 51:803-815

Kurita S (1987) Variation and evolution in the karyotype of Lycoris, Amaryllidaceae. IV. Interspecific variation in the karyotype of $L$. radiata (L'Herit.) Herb. and the origin of this triploid species. Cytologia (Tokyo) 52:137-149

Kurita S (1988) Variation and evolution in the karyotype of Lycoris, Amaryllidaceae VII. Mode of karyotype evolution within species and probable trend of karyotype evolution in the genus. Cytologia 53:323-335

Kurita S, Hsu PS (1996) Hybrid complexes in Lycoris Amaryllidaceae. Am J Bot 89:207

Kurita S, Hsu PS (1998) Cytological patterns in the Sino-Japanese flora. Hybrid complexes in Lycoris, Amaryllidaceae, In: Boufford DE, Ohba H (eds) Sino-Japanese flora its characteristics and diversification. Bul. No. 37. University Museum, Univ. Tokyo, Tokyo, Japan, pp171-180

Lee S, Kim M (1987) Palynological study of some Lycoris species. Korea J Plant Taxon 17:147-154

Lee YI, Chang FC, Chung MC (2011) Chromosome pairing affinities in interspecific hybrids reflect phylogenetic distances among lady's slipper orchids (Paphiopedilum). Ann Bot 108: $113-121$

Levan A, Fredga K, Sandberg AA (1964) Nomenclature for centromeric position on chromosomes. Hereditas 52:201-220

Ma B, Tarumoto I, Nakamura N, Kunitake H (2001) Production of interspecific hybrids between Lycoris incarnata and four other Lycoris species through embryo culture. J Jpn Soc Hort Sci 70:697-703

Marasek-Ciolakowska A, He H, Bijman P, Ramanna MS, Arens P, Van Tuyl JM (2012) Assessment of intergenomic recombination through GISH analysis of $\mathrm{F} 1, \mathrm{BC} 1$ and $\mathrm{BC} 2$ progenies of Tulipa gesneriana and T. fosteriana. Plant Syst Evol 298:887-899

Mézard C (2006) Meiotic recombination hotspots in plants. Biochem Soc Transactions 34:531-534

Mir C, Toumi L, Jarne P, Sarda V, Di Giusto F, Lumaret R (2006) Endemic North African Quercus afares Pomel originates from hybridization between two genetically very distant oak species (Q. suber $\mathrm{L}$. and $Q$. canariensisWilld.): evidence from nuclear and cytoplasmic markers. Heredity 96:175-184

Nishikawa K, Furuta Y, Endo N (1979) Consideration of the chromosome evolution on the basis of nuclear DNA content and total chromosome length in Lycoris. Jpn J Genet 54:387-396

Rieseberg LH (1997) Hybrid origins of plant species. Annu Rev Ecol Evol Syst 28:359-389

Sant'Angelo DB, Lafuse WP, Passmore HC (1992) Evidence that nucleotide sequence identity is a requirement for meiotic crossing over with the mouse Eb recombinational hotspots. Genomics 13:1334-1336

Schubert I, Lysak M (2011) Interpretation of karyotype evolution should consider chromosome structural constraints. Trends Genet 27:207-216

Shen P, Huang HV (1986) Homologous recombination in Escherichia coli : dependence on substrate length and homology. Genetics 112:441-457

Shii CT, Lee JF, Yuan MS, Chin SW (1997) Nucleotype remodelling in interspecific hybridization of Lycoris aurea $\times$ L. radiata. Acta Hort (ISHS) 430:521-528

Soltis PS, Soltis DE (2009) The role of hybridization in plant speciation. Annu Rev Plant Biol 60:561-588

Sykorova E, Lim KY, Kunicka Z et al (2003) Telomere variability in the monocotyledonous plant order Asparagales. Proc R Soc Lond B Biol Sci 270:1893-1904 
Tarumoto I, Ma B, Ogawa T (2006) Studies on speciation in genus Lycoris using interspecific hybrids and selfed plants produced through embryo rescue. Jpn Agr Res Q 40:317-326

Wu MC, Yuan MS, Shii CT (2005) The breeding in polykaryomorphic progenies of spider lily (Lycoris spp.) mediated synthetic dikaryotype hybrids $2 n=18(4 \mathrm{M}+3 \mathrm{~T}+11 \mathrm{~A})$. Acta Hort (ISHS) 673:149-154
Yuan MS, Wu CJ, Shii CT (1998) Fertility and karyotype remodel in the dikaryotype hybrids Lycoris aurea $\times$ L. radiata. J Genet Mol Biol 9:91-99

Zonneveld BJM (2009) The systematic value of nuclear genome size for "all" species of Tulipa L. (Liliaceae). Plant Syst Evol $281: 217-245$ 